\title{
DIEZ RAZONES PARA INCORPORAR EL SEGUIMIENTO DEL PRECEDENTE EN CHILE*
}

\section{LUIS IVÁN DÍAZ GARCÍA**}

RESUMEN: En el contexto de la actual discusión sobre el mecanismo recursivo para ante la Corte Suprema que se establecerá en el proyecto de Código Procesal Civil chileno en actual tramitación en el Congreso Nacional, el presente artículo desarrolla diez razones por las cuales se debería incorporar el seguimiento del precedente en todos los ámbitos procesales del ordenamiento jurídico nacional. Las cuatro primeras constituyen una respuesta a las objeciones que se han levantado en contra de esa opción, para evidenciar la debilidad de cada una de ellas. Las seis siguientes expresan argumentos de índole axiológico, lógico, económico e iusfundamental que abogan a favor de dicho seguimiento bajo una modalidad que aquí se denomina prima facie y que por tanto no considera al precedente una norma jurídica.

Palabras CLAVE: Precedente - Ratio decidendi - Argumentos - Derecho procesal - Corte Suprema.

\section{Ten Reasons to Incorporate Precedent-Following IN CHILE}

ABSTRACT: In the context of the current discussion on the resources mechanism to get to the Supreme Court, that will be established in the Chilean Civil Procedural Code draft that is being discussed in Congress, this paper develops ten reasons to incorporate precedent- fol-

Esta investigación ha sido desarrollada en el marco de la ejecución del proyecto FONDECYT No 11121310, titulado "Seguimiento del precedente por la Corte Suprema en unificación de jurisprudencia laboral”, cuyo investigador responsable es Luis Iván Díaz García. Agradezco sinceramente los significativos aportes y comentarios a una versión preliminar de este artículo realizados por los académicos de la Universidad Católica de Temuco Pablo Bravo Hurtado y Sulán Wong Ramírez, los que permitieron mejorarlo sustancialmente.

Fecha de recepción: 15 de enero de 2015

Fecha de aceptación: 5 de mayo de 2015.

** El autor es académico en la Facultad de Ciencias Jurídicas de la Universidad Católica de Temuco (Chile) e integrante del Grupo de Investigaciones Jurídicas de la misma. Abogado Pontificia Universidad Católica de Chile (ChIle). Doctor en Derecho Universidad Carlos III de Madrid (EspaÑa). Correo electrónico: ivandiaz@uct.cl 
lowing in all the procedural realms in the juridical national system. In order to make evident the weakness of each one of those, the first four reasons represent an answer to the objections that have arose against this option. The following six reasons express axiological, logical, and economic arguments, as well as arguments build on fundamental rights reasons, which support the argument for precedent under a modality, here mentioned as prima facie. Therefore, it does not consider the precedent of a juridical norm.

KEYWORDS: precedent - ratio decidendi - arguments - Procesal Law - Supreme Court

Sumario. Introducción. 1) No se atenta contra el sistema de fuentes del Civil Law. 2) No se lesiona la justicia material. 3) No se afecta la independencia judicial. 4) No empobrece ni petrifica al ordenamiento jurídico. 5) Seguridad jurídica. 6) Justicia formal e igualdad ante la justicia. 7) Corrección del discurso judicial. 8) Racionalidad del comportamiento judicial. 9) Economía en el ejercicio de la jurisdicción. 10) Tendencia comparada. Conclusiones. Bibliografía.

\section{INTRODUCCIÓN}

El ordenamiento procesal chileno parece evolucionar hacia la transformación de la Corte Suprema en un tribunal encargado de unificar la jurisprudencia, esto es, de corregir la dispersión de interpretaciones sobre una misma disposición. Así lo evidencian las diversas reformas aplicadas a los recursos que son de competencia de dicha Corte en los últimos 20 años $^{1}$. En efecto, y por una parte, tras la reforma de 1995 el recurso de casación civil fue entregado al conocimiento del pleno si lo solicita una de las partes fundada en que el máximo tribunal ha sostenido interpretaciones diversas sobre la misma materia de Derecho ${ }^{2}$. En igual dirección, el Código Procesal Penal, de progresiva aplicación a partir del año 2000 en Chile, dispone que el recurso de nulidad penal es de conocimiento

1 En este mismo sentido se pronuncia Raúl Tavolari, quien por lo demás apoya este giro en el rol de la Corte Suprema. Luego de explicar las reformas a la casación civil de 1995 y el recurso de nulidad del proceso penal, sostiene que, "imperceptiblemente, el sistema jurídico chileno tiende hacia un criterio uniformador de la jurisprudencia, alentado, además, por la especialización de las Salas de la Corte, que si contribuye a la seguridad juridica y a la certeza jurídica representará un movimiento digno de encomio". Ver TAVOlaRI, Raúl (2006). "Reflexiones sobre la Corte Suprema chilena". En Berizonce, Hitter y Oteíza (Coords.). El papel de los Tribunales Superiores. Buenos Aires: Ubinzan-Culzoni, p. 498.

2 Artículo 780 del Código de Procedimiento Civil de Chile. 
de la Corte Suprema, en lo que aquí interesa, si existe infracción de ley que ha influido sustancialmente en lo dispositivo del fallo y respecto de la materia de Derecho objeto del juicio existen diversas interpretaciones sostenidas por los tribunales superiores ${ }^{3}$. El recurso de unificación de jurisprudencia laboral, por último, es de competencia exclusiva de la Corte Suprema cuando respecto de la materia de Derecho objeto del juicio existen diversas interpretaciones sostenidas por los tribunales superiores de justicia ${ }^{4}$.

Sin embargo, y pese a la tendencia legislativa recién descrita, los recursos de casación civil reformado y de nulidad penal no han sido capaces de generar aquella uniformidad. Aunque distinta es la situación en materia laboral entre 2008 y $2013^{5}$, su impresionante inclinación pro empleador en dicho período ha mutado desde marzo de 2014 sin que sea posible anticipar si este giro generará una nueva jurisprudencia igualmente uniforme. La doctrina nacional, por su parte, se muestra mayoritariamente reacia a admitir la incorporación del seguimiento del precedente en nuestro ordenamiento jurídico.

Por su parte, el proyecto de Código Procesal Civil se encuentra en la más absoluta indefinición respecto del rol que se asignará a la Corte Suprema como cabeza del sistema jurisdiccional chileno. De este modo, a la contradicción entre las aparentes pretensiones del legislador, por una parte, y la práctica judicial prevaleciente y la opinión de la doctrina mayoritaria, por otra, se suma la incertidumbre en el aspecto procesal que mayor carga genera para el Poder Judicial.

En este escenario de contradicciones y especialmente a la luz de la oportunidad que genera la actual indefinición respecto del rol que asumirá la Corte Suprema bajo el nuevo proceso civil, resulta propicio destacar las razones por las que se debe introducir de manera decidida el seguimiento del precedente en el ordenamiento jurídico chileno. Conviene enfatizar que, por cierto, esta es la única manera de uniformar la jurisprudencia, pues mediante dicho seguimiento se evita la dispersión jurisprudencial.

Desde tales coordenadas, la pregunta que guía la presente investigación puede ser formulada del siguiente modo: ¡cuáles son las razones que obran a favor de la incorporación del seguimiento del precedente en el Derecho chileno? En otras palabras, ¿Qué argumentos se pueden ofrecer a favor de contar con una jurisprudencia uniforme a través del seguimiento

Artículo 376 respecto del artículo 373, letra b), del Código Procesal Penal de Chile.

Artículo 483 del Código del Trabajo de Chile.

Ver Díaz García, L. Iván, et al. (2014). "Seguimiento del precedente por la Corte Suprema de Chile en materia laboral. Estudio empírico del recurso de unificación de jurisprudencia". En Revista Chilena de Derecho. Vol. 41, N³, pp. 1105-1131. 
del precedente en el ámbito procesal civil y, en general, en todos los ámbitos procesales del ordenamiento jurídico nacional?

En este punto de la exposición conviene precisar qué se entiende por precedente y por seguimiento del precedente. El precedente es la razón normativa que constituye el fundamento directo o inmediato de lo decidido en un caso anterior que puede servir de guía para decidir un caso presente. En la cultura jurídica anglosajona esta razón normativa de lo decidido se denomina ratio decidendi ${ }^{6}$.

Por su parte, para explicar en qué consiste el seguimiento del precedente es necesario advertir que, según se constata en un estudio coordinado por MacCormick y Summers, existen cuatro niveles o grados de vinculación al precedente en la experiencia comparada ${ }^{7}$. De ellos interesa explicar aquí solo los dos de mayor intensidad. El grado más intenso de seguimiento del precedente se puede denominar vinculación formal. En este caso la sentencia que se aparta de la ratio decidendi aplicada en un caso anterior es ilegal y puede ser revocada mediante un recurso procesal. Como se puede apreciar, el precedente genera una norma jurídica de carácter general, tan obligatoria como las demás fuentes formales del Derecho, al punto que su inobservancia es considerada ilegal y revocable sobre la base de este mismo fundamento. Un nivel menos intenso de seguimiento del precedente puede ser denominado vinculación prima facie. En este caso el precedente constituye la interpretación que debe ser seguida por los operadores jurídicos, a menos que existan buenas razones para abandonarla. Explicando este grado de vinculación, Aleksander Peczenik explica que la decisión que no sigue el precedente es legal, pero puede ser criticada en sus fundamentos y objeto de revocación mediante recurso ${ }^{8}$. Esta vinculación prima facie es, precisamente, la que se postula en el presente trabajo.

Desde un punto de vista estructural, el discurso se ordena en torno a diez razones que argumentan a favor del seguimiento del precedente en el ordenamiento jurídico chileno. Sin embargo, entre aquellas se deben distinguir las que constituyen una respuesta a las objeciones levantadas en su contra (las cuatro primeras) de las justificaciones que aluden a los beneficios que reporta esta opción (las seis últimas) ${ }^{9}$. El discurso finaliza con las pertinentes conclusiones.

6 Llewellyng, Karl (1989): The case law system in America. Translate from the German by Michael Ansaldi. Chicago: The University of Chicago Press, p. 15.

7 MacCormick, Neil, y Summers, Robert S. (eds.) (1997). Interpreting precedents. A comparative study. Aldershot-Brookfield: Ashgate Dartmouth.

8 Peczenik, Aleksander (1997). "The binding force of precedent”. En MacCormick, Neil, y Summers, Robert S. (eds.) (1997). Interpreting precedents. A comparative study. AldershotBrookfield: Ashgate Dartmouth, p. 463.

9 De estas diez razones, tres coinciden con las mencionadas en Delgado Castro, Jordi, y DíAz García, L. Iván (2011). "La unificación de jurisprudencia pretendida por el recurso 


\section{1) No SE ATENTA CONTRA EL Sistema de FUENTES DEl CiVil LAW}

Parece posible sostener que el principal argumento de quienes se oponen a la incorporación del seguimiento del precedente es que la jurisprudencia no es fuente del Derecho. En efecto, bajo el sistema de fuentes del Civil Law las sentencias tienen un efecto relativo ${ }^{10}$, como normativamente lo expresa, por lo demás, el artículo $3^{\circ}$ del Código Civil chileno ${ }^{11}$. La labor del juez, explican los partidarios de esta perspectiva, no consiste en crear Derecho, sino en aplicarlo a casos individuales, singulares o con$\operatorname{cretos}^{12}$. "De lo contrario, las resoluciones judiciales se transformarían en normas generales, aplicables a todos los casos similares, invadiendo la competencia del legislador"13 y, por lo mismo, en fuente del Derecho ${ }^{14}$.

Conviene explicitar que la perspectiva recién esbozada no constituye tanto una afirmación normativa, sino ante todo una concepción cultural respecto del Derecho y del rol de las sentencias en el ordenamiento jurídico. Esta concepción que deja fuera del sistema de fuentes a la jurisprudencia no es neutral, sino heredera de la ideología y experiencia revolucionaria de 1789 en Francia ${ }^{15}$. En efecto, aquella se funda en una profunda desconfianza de los ilustrados franceses frente a los jueces, funcionarios del rey y contrarios al proceso revolucionario ${ }^{16}$. En esta lógica, y siguiendo a Montesquieu, el juez debía limitarse a operar como la "boca

extraordinario. Ventajas y problemas”. En Revista de Derecho, Universidad Católica del Norte, Vol. 18, $\mathrm{N}^{\circ}$ 2, pp. 275-304. Otras 3 de estas 10 razones constituyen una respuesta a algunos problemas que, de acuerdo con ese mismo artículo, derivarían de la unificación de la jurisprudencia en virtud el seguimiento del precedente.

10 El efecto relativo consiste, en esencia, en que las sentencias judiciales solo producen efecto respecto de las partes en litigio. Así se explica en las obras más tradicionales del Derecho civil chileno, como la de Claro Solar, Luis (1992): Explicaciones de Derecho civil chileno y comparado. Santiago de Chile: Jurídica de Chile, Vol. I, T.I, p. 32, y la de Alessandri R., Arturo, Somarriva U., Manuel, y Vodanovic H., Antonio (1998). Tratado de Derecho civil. Santiago de Chile: Jurídica de Chile, t. I, p. 132.

$11 \quad$ El artículo $3^{\circ}$ del Código Civil chileno textualmente prescribe: "Las sentencias judiciales no tiene fuerza obligatoria sino respecto de las causas en que actualmente se pronunciaren".

12 Halpern, Cecily, y Humeres, Héctor (2010). "La intervención de la Corte Suprema en la nueva justicia del trabajo: el recurso de unificación de jurisprudencia”. En: Actualidad Jurídica, Universidad del Desarrollo año XI, N²1, p. 353.

13 Sarmiento García, Luis E. (1984). Introducción al Derecho. Buenos Aires: Abeledo Perrot, p. 167.

14 Bordalí Salamanca, Andrés (2013). "La independencia de los jueces en la aplicación de la ley dentro de la organización judicial chilena”. En Revista Chilena de Derecho, Vol. 40, №2, agosto, p. 627.

15 Bravo-Hurtado, Pablo (2013). "Hacia los precedentes en Chile: Reforma procesal Civil y fuentes del Derecho". En Revista Chilena de Derecho, Vol. 40, N², 2013, especialmente pp. 551-553.

16 Como explica Edwin Figueroa Gutarra, la desconfianza hacia los jueces por parte de los pensadores ilustrados se debía no solo a que en el antiguo régimen monárquico eran funcionarios del rey, sino además a que con sus inmotivadas decisiones podían torcer la voluntad del legislador, único representante legítimo de la soberanía popular. Ver Figueroa 
que pronuncia las palabras de la ley" ${ }^{17}$, ley que emanaba del único depositario de la soberanía popular: el Parlamento.

Pues bien, el nivel de vinculación al precedente sugerido en este trabajo no implica transformar a la jurisprudencia en fuente del Derecho. Por lo mismo, no altera el sistema de fuentes establecido en las familias jurídicas del Civil Law ni, en consecuencia, la vigente en el ordenamiento chileno. En efecto, la ratio decidendi establecida en un caso anterior constituye un criterio de interpretación que debe ser seguido a menos que se cuente con buenas razones para abandonarlo. Según se expresó, esto se debe a que la decisión que se aparta del precedente es legal, pero puede ser criticada en sus fundamentos y por lo mismo revocada a través de un recurso procesal. De este modo se evidencia que la jurisprudencia no se constituye en fuente formal del Derecho. Tal grado de vinculación fue, por lo demás, el establecido en el proyecto de Código Procesal Civil remitido el año 2012 por el Gobierno al Congreso Nacional ${ }^{18}$.

\section{2) NO SE LESIONA LA JUSTICIA MATERIAL}

La justicia es, para muchos, el principal o a lo menos uno de los principales valores que el Derecho ha de realizar ${ }^{19}$. Pues bien, otro de los argumentos que se esgrime en contra del seguimiento del precedente es que en muchos casos se atenta en contra de este valor, específicamente en el sentido de "justicia material" ${ }^{20}$. Con esta expresión se alude a lo que es justo a partir de las circunstancias del caso que debe ser resuelto ${ }^{21}$. Adap-

Gutarra, Edwin (sin fecha). "Precedentes vinculantes: ¿consolidación normativa o restricciones a las facultades interpretativas de los jueces?”, pp. 3 y 4.

17 Montesquieu (1984). Del espíritu de las leyes. (Traducción de Nicolás Estévanez). Buenos Aires, Editorial Heliasta, sexta edición, p. 194.

18 En este mismo sentido, Bravo-Hurtado (2013) especialmente 567-569. Conviene advertir que tras su aprobación por la Cámara de Diputados el proyecto de Código Procesal Civil quedó sin medios de impugnación para ante la Corte Suprema.

19 Latorre, Ángel (1991). Introducción al Derecho. Barcelona: Ariel, séptima edición, p. 43; y Escandón Alomar, Jesús (2008) Curso de Introducción al Derecho. Concepción: Universidad de Concepción, p. 5.

20 Un ejemplo paradigmático de esta objeción se encuentra en el estudio desarrollado por Jaime Couso en el que se desentrañan las razones del fracaso del seguimiento del precedente en materia penal por parte de la Corte Suprema. Al respecto expresa el autor que "[u]na primera razón cultural es la vocación de buscar la "justicia material" en el caso concreto". Ver Couso Salas, Jaime (2007). "El rol uniformador de la sala penal de la Corte Suprema. Anatomía de un fracaso". En Revista de Derecho, Universidad Austral, Vol. XX, No 2, diciembre, pp. 160 y 161.

21 Esta precisión es necesaria debido a que la expresión "justicia material" no solo se utiliza en un sentido que se puede denominar "procesal", sino también con un significado que se puede calificar de "social". En este último caso alude al mejoramiento de las condiciones de vida de la población de menores ingresos, como deber del Estado. En tal sentido ver, por ejemplo, Marshall Barberán, Pablo (2010). "El Estado de Derecho como principio y su 
tando la famosa definición de Ulpiano, la justicia material consistiría en la voluntad de dar a cada uno lo suyo, debiendo determinarse lo suyo de cada cual en el caso concreto.

Pues bien, la dicotomía entre seguimiento del precedente y justicia material no es más que una intuición injustificada. Por cierto es un error seguramente inadvertido y ciertamente bien intencionado, pues lo que en última instancia rechaza es que el seguimiento del precedente conduzca a una solución injusta. Pese a esta buena intención, la contradicción debe ser desmentida en atención a las siguientes consideraciones.

Como acertadamente expresa Squella, la historia de las ideas jurídicas, políticas y morales enseña que los seres humanos han forjado múltiples y diversos ideales de justicia ${ }^{22}$. Estos diversos ideales o concepciones de justicia conducen o pueden conducir a que se discrepe respecto de qué es lo materialmente justo en el caso concreto. Si esto es efectivo, se plantean a lo menos dos interrogantes fundamentales. Primero, ¿cuál de las opciones interpretativas recoge de mejor manera la justicia material? Segundo, y en íntima conexión con la anterior, ¿quién se encuentra calificado para determinar cuál de esas opciones interpretativas recoge de mejor manera la justicia material?

Suponiendo que se contara con adecuadas respuestas para ambas preguntas (es decir, que se sabe cuál es la interpretación materialmente justa y que está claro a quién corresponde dicha calificación), los escenarios posibles son esencialmente tres. El primero de ellos es que lo previamente resuelto coincide con lo que se considera materialmente justo. En tal caso, no existirá contradicción entre este valor y la exigencia de resolver del mismo modo los casos posteriores iguales a aquel en el que se estableció el precedente.

El segundo de tales escenarios es que lo previamente resuelto diverge de lo exigido por la justicia material. Esta disconformidad puede provenir de una involuntariamente errónea percepción de lo que es materialmente justo ${ }^{23}$, o de un cambio en los criterios o valores predominantes que conducen a definir lo que es materialmente justo ${ }^{24}$. En cualquiera de

consagración en la Constitución Política”. En Revista de Derecho, Universidad Católica del Norte, año $17, \mathrm{~N}^{\circ} 2$, pp. 185-204.

22 Squella Narducci, Agustín (2011) Introducción al Derecho, Santiago de Chile: Jurídica de Chile, segunda edición, p. 729.

23 Esto se debe, como acertadamente expresa Rescher, a que "Lo que a lo sumo podemos hacer (y lo que a lo sumo se nos puede pedir en nombre de la racionalidad) es lo mejor que podamos en determinadas condiciones. Pero nada nos asegura qué es en realidad lo óptimo, no hay garantía de que lo que parece lo mejor, de hecho lo sea". Ver Rescher, Nicholas (1993). La racionalidad. Una indagación filosófica sobre la naturaleza y la justificación de la razón. Traducción de Susana Nuccetelli. Madrid: Tecnos, p. 45.

$24 \quad$ Sobre el punto, expresa LAREnz: "La jurisprudencia de los tribunales no puede verse libre, por mucho tiempo, de tales mutaciones si quiere seguir estando en consonancia con la conciencia 
estos dos eventos, siempre subsiste la posibilidad de reemplazar el precedente a partir de nuevas valoraciones sobre el contenido o efectos de la norma. De este modo también se elimina la posible contradicción entre lo justo y el precedente, mediante la sustitución del primero por otro mejor justificado.

La tercera posibilidad consiste en que exista una diferencia entre el caso actual, en el que se pretende la aplicación del precedente, y aquel en el que este último fue establecido. Al respecto conviene recordar que la aplicación del precedente no exige identidad ${ }^{25}$, sino igualdad. La igualdad consiste en que los casos en comparación coinciden en la totalidad de sus propiedades relevantes ${ }^{26}$. Por lo mismo, si existe divergencia en alguna de las propiedades relevantes de los casos en comparación, resulta perfectamente posible apartarse del precedente. En cualquier caso, corresponderá al juzgador explicar en qué consiste la diferencia ${ }^{27}$. En este último escenario tampoco subsiste una contraposición entre lo justo y el precedente.

Lo expresado evidencia que el seguimiento del precedente no sacrifica el valor de la justicia material. Esto se debe a que en algunos casos no existe dicha contradicción, en otros el precedente puede ser abandonado y en un tercer grupo resulta improcedente su aplicación.

\section{3) NO SE AFECTA LA INDEPENDENCIA JUDICIAL}

Otro de los argumentos que habitualmente se invocan para rechazar el precedente vinculante es la independencia de los jueces ${ }^{28}$. Por cierto en este caso la independencia se entiende en el sentido que cada juez puede adoptar su propia interpretación de las disposiciones que aplica. Al respecto Pablo Bravo-Hurtado explica que en Chile "está instalada la idea de que la independencia judicial significa que el juez inferior es libre de tener su propio criterio jurídico, distinto al de los superiores, y que no es criticable por eso" ${ }^{29}$. Sin embargo, no es este el significado de la independencia de los jueces, como se verá de inmediato.

juridica y moral generales". LAREnz, Karl (1994) Metodología de la ciencia del Derecho. Traducción de Marcelino Rodríguez Molinero. Barcelona, Ariel, p. 288.

25 De cualquier modo, dos casos nunca coinciden en la totalidad de sus propiedades. Cfr. Alexy, Robert (2001) Teoría de los derechos fundamentales. Traducción de Ernesto Garzón Valdés. Madrid: Centro de Estudios Políticos y Constitucionales, pp. 386 y 387.

26 Comanducci, Paolo (1999). 84.

27 Mendonca, Daniel, y Guibourg, Ricardo A. (2004) La odisea constitucional. Constitución, teoría y método. Madrid: Marcial Pons, p. 180.

28 En este sentido se puede ver, por ejemplo, Herrera Carbucia, Manuel Ramón (2006) "Importancia de la unidad de la jurisprudencia laboral. Análisis y discusión". En Gaceta Laboral, Vol. 12, $\mathrm{N}^{\circ}$ 1, p. 134; y, aunque con ciertos matices, Remón Peñalver, Jesús (2006) "La lucha por la seguridad jurídica". Madrid: La Ley, p. 70. 
En efecto, si esta forma de entender la independencia judicial fuera correcta, entonces el seguimiento del precedente atentaría en contra de aquella. Y si esto fuera cierto, entonces ningún juez de la familia del Common Law sería independiente. Una tal afirmación no es, desde luego, sostenible. Esta constatación resulta por sí sola suficientemente sólida para rechazar la referida interpretación y recomienda, de paso, precisar qué significa, entonces, la independencia judicial.

Al respecto conviene recordar que la independencia judicial es un derecho fundamental, otorgado tanto por la Constitución chilena como por el Derecho Internacional de los Derechos Humanos. En efecto, la Constitución confiere el derecho fundamental al proceso justo, también conocido como debido proceso legal ${ }^{30}$. El Tribunal Constitucional, por su parte, ha precisado que es un elemento esencial de este derecho que el juzgador sea objetivamente independiente ${ }^{31}$. En el ámbito internacional, por su parte, se trata de un derecho expresamente mencionado en diversos instrumentos, tales como la Declaración Universal de Derechos Humanos (artículo 10), el Pacto Internacional de Derechos Civiles y Políticos (artículo 14.1) y la Convención Americana de Derechos Humanos (artículo 8.1).

Pues bien, como ha declarado la Asamblea General de Naciones Unidas, la independencia judicial consiste en que los jueces deben resolver los asuntos que han de juzgar "sin restricción alguna y sin influencias, alicientes, presiones, amenazas o intromisiones indebidas, sean directas o indirectas, de cualquiera sectores o por cualquier motivo" 32 . La esencia de esta independencia radica en que los jueces no sean influenciados o controlados por el gobierno al momento de resolver los casos sometidos a su decisión ${ }^{33}$. Por

30 Al respecto dispone el artículo 19, $\mathrm{N}^{\circ} 3$, inciso sexto, de la Constitución chilena que corresponderá siempre al legislador establecer las bases de un racional y justo procedimiento. Al respecto textualmente sostuvo el Tribunal Constitucional de Chile que "todo juzgamiento debe emanar de un órgano objetivamente independiente y subjetivamente imparcial, elementos esenciales del debido proceso que consagra toda la doctrina procesal contemporánea”. Ver Tribunal Constitucional de Chile, 11 de diciembre de 2012, rol $\mathrm{N}^{\circ}$ 2041-2011, Requerimiento de inaplicabilidad por inconstitucionalidad de Inversiones Alce S.A. respecto del artículo 115, inciso $1^{\circ}$ del Código Tributario, en los autos sobre reclamación Tributaria, caratulados "Inversiones Alce S.A. con Servicio de Impuestos Internos", del que conoce el Tribunal Tributario de la ciudad de Temuco, bajo el Rol $\mathrm{N}^{\circ}$ 10.057, considerando octavo. En el mismo sentido ver Tribunal Constitucional De Chile, 30 de diciembre de 2008, rol N ${ }^{\circ}$ 1243-2008, Control de constitucionalidad del proyecto de ley, aprobado por el Congreso Nacional, que fortalece y perfecciona la jurisdicción tributaria (Boletín $\mathrm{N}^{\circ}$ 3139-05), considerando duodécimo segundo. Asamblea General de las Naciones Unidas (1985) Principios básicos relativos a la independencia de la judicatura. Resoluciones 4032, del 29 de noviembre de 1985 y 40 i1 46. del 13 de diciembre de 1985, número 2.

33 Castagnola, Andrea (2010) "La diversidad institucional de los poderes judiciales provinciales en Argentina desde una perspectiva histórica". En Postdata (Buenos Aires), Vol.15, N², jul.-dic. 2010, sin paginación. 
cierto tampoco deben recibir órdenes o instrucciones por parte de otros órganos del Estado ni, en lo que aquí interesa, por jueces o tribunales de mayor jerarquía respecto de cómo resolver un caso concreto ${ }^{34}$.

La independencia en el sentido de "no intromisión" se vincula estrechamente con el principio de "independencia y única sumisión a la ley" a que aluden tanto Carlos Del Río35, como Luis Rodríguez y María Magdalena Ossandón ${ }^{36}$. En efecto, la idea de única sumisión a la ley consiste en que los jueces deben proceder con estricta sujeción a la ley, tanto en la tramitación de los procesos como en la dictación de sentencia ${ }^{37}$. Esta idea complementa la noción de independencia judicial, pues ańade a la perspectiva de no intromisión la dimensión de sumisión a la ley. Por cierto esta dimensión no se opone al seguimiento del precedente, pues la sujeción a la ley se complementa con una determinada interpretación de esta última.

En suma, la independencia judicial no significa que el juez inferior tiene derecho a interpretar una disposición del modo que mejor le parezca, por cierto diversa a los tribunales superiores. Lejos de ello, este derecho fundamental consiste en la ausencia de alicientes, presiones o amenazas sobre el juez al momento de resolver un caso concreto, sea que provengan desde integrantes del propio Poder Judicial, desde el Gobierno o en general desde cualquier tercero. De este modo, la independencia judicial nada tiene que ver con el significado que se le atribuye al momento de transformarla en un argumento en contra del seguimiento del precedente.

\section{NO EMPOBRECE NI PETRIFICA AL ORDENAMIENTO JURÍDICO}

Otro de los argumentos que se presenta en oposición al seguimiento del precedente es que se empobrece y petrifica el ordenamiento jurídico. Al respecto Manuel Herrera afirma que dicho seguimiento "no favorece en su aplicación mecánica y literal a una jurisprudencia más reflexiva, más lógica, más crítica" 38 . En similar sentido, Jordi Nieva opina que la riqueza

\footnotetext{
34 En similar sentido, precisa Rafael DE Asís que "cuando se destaca en estos casos el valor de la independencia se hace pensando en posibles instrucciones u órdenes de órganos superiores a inferiores". Ver De Asís Roig, Rafael (2004). "Imparcialidad, Igualdad y obediencia en la actividad judicial". En Doxa (Alicante), N 15-16, p. 923.

35 Del Río Ferreti, Carlos (2010). "Tres apuntes sobre el recurso de nulidad y el enjuiciamiento fáctico a propósito de tres fallos de la Ilustrísima Corte de Apelaciones de La Serena". En Revista de Derecho, Universidad Católica del Norte (Coquimbo), año 17, № 2, nota al pie 5 de la p. 134 .

36 Rodríguez Collao, Luis, y Ossandón Widow, María Magdalena (2005). "Aspectos sistemáticos y político-criminales de la prevaricación admnistrativa”. En Revista de Derecho (Valparaíso), vol. XXVI, 2005, segundo semestre, p. 412.

37 Casarino Viterbo, Mario (2008). Manual de Derecho procesal, tomo I, Jurídica de Chile, Santiago de Chile, reimpresión de la sexta edición, p. 54.

38 Herrera Carbucia (2006) 134.
} 
del ordenamiento jurídico se basa en que la jurisprudencia no permanezca estática. De este modo, ańade, "si el valor principal es conservar la jurisprudencia, el ordenamiento jurídico positivo no acaba siendo más que un pretexto para construir esa jurisprudencia”. Por lo mismo, sostiene, mientras el ordenamiento jurídico no es reformado "la jurisprudencia continúa siendo la misma, porque, evidentemente, humanamente es mucho más cómodo y sencillo mantenerla que modificarla, teniendo que justificar por que"'39.

Para enfrentar esta objeción conviene recordar que el grado de vinculación al precedente que se postula en este trabajo es el denominado seguimiento prima facie. Bajo este grado de vinculación, con acierto expresa Rafael DE Asís que "la defensa del valor del precedente solo va en la línea de exigir que el abandono de criterios anteriores se justifique expresamente" 40 . En este sentido, y siguiendo ahora a AlEXY, se puede afirmar que las interpretaciones sostenidas en los precedentes "poseen solo una fuerza vinculante prima facie" 41 . En efecto, el juzgador puede apartarse de las interpretaciones establecidas si ofrece una fundamentación suficiente y razonable ${ }^{42}$.

Con todo, conviene destacar que el ofrecimiento de buenas razones para apartarse del precedente no conduce de manera necesaria a esta consecuencia. En efecto, junto con aquellas se puede contar también con buenas razones para mantener la aplicación del mismo. Para decirlo todavía más claramente, el seguimiento del precedente es un punto de partida de toda decisión judicial. Apartarse del mismo puede provenir del ofrecimiento de buenas razones para ello. Sin embargo, y al mismo tiempo, mejores razones pueden conducir a mantenerse en la línea interpretativa establecida por aquel ${ }^{43}$. Este intercambio de argumentos (que pueden ser

39 Y concluye Jordi Nieva: “Finalmente, el Tribunal Supremo se acaba convirtiendo en un órgano de inadmisión de recursos, asi como de conservación de la jurisprudencia como si de una reliquia se tratase. Y el ordenamiento juridico se queda sin su principal acicate: el Tribunal Supremo". Nieva Fenoll, Jordi (2006). "La reforma de la labor del Tribunal Supremo y la unificación de doctrina. Perspectivas de la introducción del modelo anglosajón en nuestro Derecho”. En Diario La Ley, sección Doctrina, 4 de enero de 2006, año XXVII, Editorial La Ley.

40 DE Asís Roig, Rafael (1995). Jueces y normas. La decisión judicial desde el ordenamiento. Madrid: Marcial Pons, p. 275.

$41 \quad$ Alexy (2001) 538 y 539.

42 Sobre el punto expresa Remón Peñalver: "se vulnera el principio de igualdad, en su vertiente de derecho a la igualdad en aplicación de la Ley, cuando el mismo órgano judicial, existiendo identidad sustancial del supuesto de hecho enjuiciado, se aparta del criterio mantenido en casos anteriores, sin que medie una fundamentación suficiente y razonable que justifique la nueva postura en la interpretación y aplicación de la misma legalidad. Nada más". Ver Remón Peñalver (2006) 70.

43 Estas consideraciones no son más que la aplicación de las siguientes ideas ofrecidas por AleXY: "Si el interlocutor, obligado por la regla de fundamentación, ha dado una razón, solo está obligado a una nueva respuesta en caso de un contraargumento". Ver Alexy, Robert (1999). Teoría de la argumentación juridica. Traducción de Manuel Atienza e Isabel Espejo. Madrid: Centro de Estudios Constitucionales, primera reimpresión, p. 192. 
ofrecidos por la doctrina o por la jurisprudencia) lejos de empobrecer al Derecho, lo enriquece.

En síntesis, de ninguna manera se puede sostener que el seguimiento del precedente petrifica o empobrece la evolución del Derecho. Lo que hace es exigir buenas razones para modificar el significado que se ha atribuido a un enunciado normativo. Si se carece de esas buenas razones, entonces la interpretación ofrecida por el precedente debe ser mantenida.

\section{5) Seguridad jurídica}

La seguridad jurídica, como acertadamente sintetiza Luiz Guilherme MARINONI, consiste en la "estabilidad y continuidad del orden jurídico y previsibilidad de las consecuencias jurídicas de determinada conducta" 44 . Constituye uno de los valores que la doctrina habitualmente menciona como horizonte del Derecho ${ }^{45}$, con notable impacto tanto en el ámbito económico como político. En efecto, y desde un punto de vista económico, la seguridad jurídica tiene una relevancia especial en el crecimiento de los Estados desde que, por ejemplo, determina las posibilidades de captar la inversión extranjera ${ }^{46}$. Desde una perspectiva política, por su parte, se trata de un valor que constituye fundamento de los derechos fundamenta$\operatorname{les}^{47}$ y que viabiliza la existencia del Estado de Derecho ${ }^{48}$.

De acuerdo con la definición ofrecida, la seguridad jurídica exige certeza en cuanto a la existencia de las normas jurídicas (existencia formal), eficacia en el medio social (existencia real) y predictibilidad al momento de su aplicación a casos concretos (interpretación ${ }^{49}$. En lo que sigue interesa decir algo más sobre este último aspecto, en cuanto función radicada en el conjunto de tribunales que forman el Poder Judicial.

Bajo la lógica ilustrada el razonamiento judicial fue explicado como un simple silogismo, pues de este modo se aseguraba que el juez sería un

\footnotetext{
44 Marinoni, Luiz Guilherme (2012) “El precedente en la dimensión de la seguridad jurídica”. En Ius et Praxis, Año 18, No 1, p. 250.

45 Ver, por ejemplo, SQuella Narducci (2011) 713 y siguientes.

46 Espinosa Quintero, Leonardo (2010). "Hacia la arbitrabilidad como regla general en el sistema actual colombiano". En Revista de Derecho (Barranquilla), N³, julio-diciembre 2010, pp. 179 y 180.

47 Peces-Barba Martínez, Gregorio, con la colaboración de De Asís Roig, Rafael; Fernández Liesa, Carlos R.; y Llamas Cascón, Ángel (1999) Curso de derechos fundamentales. Madrid: Universidad Carlos III de Madrid y Boletín Oficial del Estado, primera reimpresión, pp. 245 y 246.

48 Marinoni (2012) 250.

49 En similar sentido, Garrido Gómez, María Isabel (2009) "La predecibilidad de las decisiones judiciales". En Ius et Praxis, Vol. 15, $\mathrm{N}^{\circ} 1$, pp. 63.
} 
"mero ejecutor fiel y pasivo de los dictados del legislador" 50. Sin embargo, y como destaca REMón, "si se quiere utilizar la figura lógica del silogismo, siendo la norma su premisa mayor y la subordinación de un hecho (el "caso») la menor, nadie podrá discutir el carácter esencialmente problemático del procedimiento de formación de las premisas" 51.

El carácter problemático de la formación de la premisa mayor deriva de la imprecisión que caracteriza el lenguaje jurídico, y que ha sido intensamente analizado por la filosofía analítica. Esta indeterminación exige interpretar los enunciados normativos con la finalidad de identificar la norma que en ellos se expresa. Sin embargo, no está claro cuántos ni cuáles son los criterios que se deben utilizar al efecto ${ }^{52}$, no existe una ordenación jerárquica entre todos ellos ${ }^{53}$, de modo que tampoco se sabe cuál se debe utilizar en un caso determinado ${ }^{54}$, y no está claro el significado de cada uno de esos criterios de interpretación ${ }^{55}$. Por otra parte, el proceso de interpretación es inevitablemente valorativo, pues depende, por ejemplo, de la concepción que mantenga el intérprete sobre el Derecho $^{56}$, la lógica desde la cual se justifica la interpretación del enunciado normativo ${ }^{57}$, la complejidad de los asuntos sobre los cuales debe recaer la decisión ${ }^{58}$, y la inexistencia de enunciados normativos en los que el caso pueda ser subsumido (lagunas jurídicas). Por todo esto, acierta la doctrina que concluye que no existen interpretaciones correctas ${ }^{59}$, sino interpretaciones mejor o peor justificadas.

Toda esta incertidumbre que genera la interpretación del Derecho, quebrando sobre todo la previsibilidad de las consecuencias jurídicas de determinada conducta, no es insalvable. El seguimiento del precedente es la vía a través de la cual resulta previsible para los litigantes que su caso actual será resuelto de la misma manera que un caso anterior igual al suyo. Esto se debe a que la ratio decidendi establecida para un caso anterior igual al que debe ser resuelto en el presente constituye la inter-

50 Serra Cristóbal, Rosario (2004) La libertad ideológica del juez. Valencia: Tirant lo Blanch, p. 72 .

51 Remón Peñalver (2006) 66.

52 En este sentido, Barranco Avilés, María del Carmen (2004). Derechos y decisiones interpretativas. Madrid: Marcial Pons, p. 71.

53 DE Asís Roig, Rafael (2005) El juez y la motivación en el Derecho. Madrid: Dykinson, p. 96.

54 Ver Cueto Rúa, Julio C. (1998) "La axiología jurídica y la selección de métodos de interpretación”. En Doxa (Alicante) 1998, N²1-II, p. 112; y Alexy (1999) 24.

55 En el mismo sentido, Alexy (1999) 25; y Barranco Avilés (2004) 71.

56 Peces-Barba Martínez (1999) 573.

57 Alchourrón, Carlos (2000) “Sobre Derecho y lógica”. Traducción de Jorge L. Rodríguez con la colaboración de Sergio A. Militello. En Isonomía, octubre, N 13, p. 11. De Asís Roig (1995) 223.

Ver Aarnio, Aulis (1990) La tesis de la única respuesta correcta y el principio regulativo del razonamiento jurídico". Traducción de Josep Aguiló Regla. En Doxa, N 8, p. 24. 
pretación que ha de ser aplicada para resolver este último. De este modo, el seguimiento del precedente permite excluir las demás interpretaciones posibles, eliminando o atenuando sensiblemente la pluralidad de opciones que precisamente genera la referida incertidumbre ${ }^{60}$. Esta conclusión es coherente con la perspectiva anglosajona, que sostiene que la principal justificación del seguimiento del precedente es que otorga certeza en la aplicación del Derecho ${ }^{61}$, facilitando la consistencia en la adopción de decisiones por parte del Poder Judicial ${ }^{62}$.

\section{6) JUSTICIA FORMAL E IGUALDAD ANTE LA JUSTICIA}

Más arriba se ha mostrado que no es efectivo que el seguimiento del precedente atente en contra de la justicia material. En lo que sigue se evidenciará que, en cambio, dicho seguimiento permite satisfacer otra de las dimensiones de la justicia. Se trata de aquella dimensión que exige que los casos iguales sean resueltos de la misma manera, lo que habitualmente se denomina justicia formal ${ }^{63}$. En este sentido, lo suyo de quien presenta su pretensión al juzgador consiste en que su caso debe ser decidido del mismo modo que el caso anterior igual al suyo ${ }^{64}$. Refiriéndose a esta misma idea, con acierto expresa LARENZ que "es un postulado fundamental de la justicia que "casos iguales" deben ser tratados igualmente" 65.

60 El precedente no elimina de manera necesaria la incertidumbre, desde que siempre pueden darse razones para modificar la ratio decidendi aplicada por el órgano jurisdiccional competente. "Eso no quiere decir que la eliminación de la duda interpretativa es factible, pero que sí se pueden y deben minimizar, en la medida de lo posible, las divergencias interpretativas acerca de las normas, colaborándose, de tal suerte, para la protección de la previsibilidad, indispensable al encuentro de la seguridad jurídica”. Ver MARINONi, (2012) 254.

61 En palabras de MALtz, la justificación más habitual para la doctrina del stare decisis reside en la necesidad de otorgar certeza en la aplicación del derecho. En la planificación de sus asuntos, se argumenta, la gente debe ser capaz de predecir las consecuencias legales de sus acciones. Tal predecibilidad solo puede ser obtenida si se puede esperar que los jueces siguen los precedentes al adoptar sus decisiones. Ver Maltz, Earl (1988). "The nature of precedent". North Carolina Law Review, January, p. 368.

$62 \mathrm{Al}$ respecto expresa Duxbury que El precedente tiene autoridad por una variedad de razones. Talvez la razón más comúnmente citada es que aceptar los precedentes como imperativos es facilitar la consistencia y corrección en la adopción de decisiones. DuXBURY, Neil (2008). The nature and authority of precedent. United Kingdom: Cambridge University Press, p. 24.

63 En el mismo sentido Mendonca y Guibourg afirman: "Tratar los casos iguales de manera igual es una de las formulaciones típicas de la regla de justicia”, y precisan que la regla de justicia lo es de la justicia formal, esto es, la igualdad en la aplicación de la ley. Ver Mendonca y Guibourg (2004) 185 y 186.

64 En este sentido, "llamamos justo a un acto o incluso a la ley misma, en cuanto respeta un criterio básico de igualdad”. LatorRe (1991) 44.

65 LARENZ (1994) 287. 
La justicia formal, que desde una perspectiva filosófica constituye un valor, desde el punto de vista jurídico constituye un derecho fundamental en el ordenamiento jurídico chileno. Este derecho fundamental recibe el nombre de igualdad ante la justicia ${ }^{66}$ o igualdad en la aplicación de la ley ${ }^{67}$. Habitualmente es explicado como una exigencia dirigida al juzgador ${ }^{68}$, aunque algunos lo refieren también de manera general a toda autoridad ${ }^{69}$. En virtud del mismo el juzgador debe resolver de la misma manera los casos iguales, que es precisamente el significado de la justicia formal.

Pues bien, el seguimiento del precedente concreta la justicia formal como valor y viabiliza el efectivo disfrute de su equivalente normativo, esto es, la igualdad ante la justicia o igualdad en la aplicación de la ley como derecho fundamental. Para justificar este aserto conviene explicar, en primer lugar, la estructura del razonamiento judicial para exponer luego el modo en que el seguimiento del precedente se inserta en dicho razonamiento.

A partir de las acertadas descripciones de Luigi FerRajoli ${ }^{70}$ y DE RAFAEL DE Asís ${ }^{71}$, resulta posible sostener que el razonamiento judicial se vertebra en torno a un juicio de hecho o inducción fáctica, un juicio de Derecho o deducción jurídica, y una conclusión o silogismo práctico. El primero consiste en precisar si los hechos de la demanda civil o de la acusación penal son efectivos (conclusión), a partir de las pruebas disponibles (premisas). La segunda consiste en definir si el hecho acreditado se encuentra denotado por alguna norma jurídica (conclusión) a partir de la referida conclusión fáctica y de la norma aplicable a la misma (premisas). La tercera consiste en determinar las consecuencias jurídicas aplicables al caso (conclusión) a partir de la denotación jurídica recién explicada y de la norma que determina las consecuencias aplicables al hecho (premisas).

66 Ver, por ejemplo, Verdugo y Pfeffer en Verdugo Marinkovic, Mario, Pfeffer Urquiaga, Emilio, y Nogueira Alcalá, Humberto (2002) Derecho constitucional. Santiago de Chile: Jurídica de Chile, t. I, segunda edición, pp. 214 y 217; y Molina Guarta, Hernán (2006). Derecho constitucional. Santiago de Chile: LexisNexis, pp. 260 y 262.

67 Ver, por ejemplo, Figueroa García-Huidobro, Rodolfo (2000) "Igualdad y discriminación", p. 34.

68 En este sentido ver, por ejemplo, Verdugo y Pfeffer en Verdugo / Ppeffer / Nogueira (2002) 217; y Molina Guaita (2006) 262; y Cea Egaña, José Luis (2004). Derecho constitucional chileno. Santiago de Chile: Ediciones Universidad Católica de Chile, t. II, p. 141.

69 Al respecto ver Evans De LA CuAdra, Enrique (2004) Los derechos constitucionales. Santiago de chile: Jurídica de Chile, tomo II, tercera edición, p. 140; y Figueroa García-Huidobro (2000) 34 .

70 Ferrajoli, Luigi (1998) Derecho y razón. Teoría del garantismo penal. Traducción de Perfecto Andrés Ibáńez, Alfonso Ruiz Miguel, Juan Carlos Bayón Mohino, Juan Terradillos Basoco y Rocío Cantarero Bandrés. España: Trotta, tercera edición, p. 64.

71 De Asís Roig (1995) 102, 104 y 165. 
El seguimiento del precedente, por su parte, supone una coincidencia fáctica y provoca una coincidencia normativa. Fáctica, por cuanto sostener que dos casos son iguales importa afirmar que los hechos que han de ser enjuiciados en uno y otro coinciden en todas sus propiedades relevantes, lo que es precisamente condición de aplicación del preceden$\mathrm{te}^{72}$. Normativa, por cuanto seguir el precedente consiste, precisamente, en aplicar la misma ratio decidendi, es decir, la misma razón jurídica que ha servido de base a la decisión anterior, como razón jurídica para la decisión del caso actual ${ }^{73}$. Esta coincidencia fáctica, es decir, en el juicio de hecho o inducción fáctica, y jurídica, esto es, en el juicio de Derecho o deducción jurídica, no puede conducir sino a que el caso actual sea decidido de la misma manera que el anterior, esto es, a la misma conclusión o silogismo práctico.

\section{7) CORRECCIÓN DEL DISCURSO JUdiCIAL}

Como acertadamente expresa Alexy, en el discurso práctico general existen ciertas reglas fundamentales que son "condición de posibilidad de cualquier comunicación lingüistica en que se trate de la verdad o corrección". Una de esas reglas fundamentales es la siguiente: "Todo hablante que aplique un predicado $F$ a un objeto $A$ debe estar dispuesto a aplicar $F$ también a cualquier otro objeto igual a $A$ en todos los aspectos relevantes" 74 . Esta regla, llamada regla de la universabilidad, se refiere a la coherencia de un único hablante, según explica el autor alemán. Este único hablante es cada juez y, simultáneamente, el Poder Judicial en su conjunto, como se verá e el siguiente apartado.

El discurso jurídico, y singularmente el de los jueces, es un discurso práctico, esto es, una actividad lingüística relativa a la corrección de enunciados normativos ${ }^{75}$. En efecto, de lo que se trata en el discurso judicial contenido en una sentencia es de explicar por qué se debe aplicar una determinada consecuencia jurídica a un hecho que se tiene por acreditado. De acuerdo con el principio de universabilidad, la corrección de

\footnotetext{
72 Afirmar que dos casos son iguales de ninguna manera significa sostener que los hechos de uno y otro son idénticos. En efecto, existe igualdad cuando se produce coincidencia únicamente en las propiedades relevantes de los casos en comparación, mientras que existe identidad cuando hay coincidencia en la totalidad de las propiedades de uno y otro, sin importar si las mismas son relevantes o no lo son. Al respecto ver Comanducci (1999) 84 y siguientes.

73 Llewellyng (1989) 15. En similar sentido, Whittaker, Simon (2008) "El precedente en el derecho inglés: una visión desde la ciudadela”. Traducción de Cristián Banfi del Río. En Revista Chilena de Derecho, Vol. 35, N 1, pp. 49 y 50.

$74 \quad$ Alexy (1999) 185.

75 Alexy (1999) 34.
} 
este discurso exige que quien aplica un determinado predicado (la consecuencia jurídica) a un cierto caso, debe estar dispuesto a aplicar el mismo predicado (la consecuencia jurídica) a todos los casos iguales al anterior ${ }^{76}$.

Lo expresado permite advertir la estrecha y bidireccional relación existente entre el principio de universabilidad y el seguimiento del precedente. En efecto, y por una parte, el primero constituye el fundamento del segundo, desde que constituye condición de corrección del discurso práctico, y en particular del que ofrecen los jueces en sus sentencias, aplicar la misma consecuencia jurídica a los casos iguales ${ }^{77}$. Por otra parte, y al mismo tiempo, el segundo constituye la traducción jurídica del primero $^{78}$, porque exige resolver de la misma manera los casos iguales, es decir, aplicar el principio discursivo de la universabilidad. En este sentido, el también denominado principio de la inercia "exige mantener la interpretación que sirve para solucionar un supuesto en todos los supuestos similares, exigiéndose que su abandono se haga con una suficiente justificación"79.

Conviene destacar que la regla de universabilidad no mira solo hacia las decisiones pasadas. También mira hacia las decisiones futuras. Eso significa que el juzgador no solo debe decidir un caso aplicando la ratio decidendi establecida en un caso anterior. Además debe decidir el presente caso en el mismo sentido que estaría dispuesto a resolver un caso igual en el futuro. Es precisamente por ello que el seguimiento del precedente como aplicación del principio de universalidad constituye una herramienta contra la arbitrariedad judicial ${ }^{80}$, o, si se prefiere, una garantía de imparcialidad en la toma de decisiones por parte de los jueces ${ }^{81}$.

76 En similar sentido, aunque explicando el principio de universabilidad en Habermas, Salmerón, Fernando (1991) "Comentario a la ponencia de Francisco Miró Quesada". En Sobrevilla, David (compilador). El Derecho, la politica y la ética (Actas del II Coloquio Alemán-Latinoamericano de Filosofía, Lima, 1987). México: Siglo XXI, p. 148.

$77 \quad$ Alexy (1999) 262.

78 Gascón Abellán, Marina (1993-1994) “Igualdad y respeto al precedente". En Derechos y Libertades, año $1, \mathrm{~N}^{\circ} 2$, p. 225.

79 De Asís Roig (1995) nota al pie 68 de la p. 194.

80 En este mismo sentido, María Victoria PArra explica que el principio de universabilidad "supone que el significado que un juez ofrece a un enunciado normativo, sea enunciado en términos universales, con lo cual se logra establecer normas interpretativas universales, que constituyen barreras contra la arbitrariedad, en tanto los jueces decidirán los casos, de manera similar a como fueron resueltos en el pasado y a como se resolverán en el futuro". Ver PARRA, María Victoria (2004) "El precedente judicial en el Derecho comparado". En Criterio Jurídico, $\mathrm{N}^{\circ} 4$, pp. 250 y 251.

81 Analógicamente, Juan Antonio García Amado explica que el principio de universabilidad es procedimental y pretende asegurar la imparcialidad de la norma que deriva del discurso racional. Ver García Amado, Juan Antonio (1994) "Justicia, democracia y validez del Derecho en Jürgen Habermas”. En Koch, Hans-Joachm, y Neumann, Ulfrid (eds.). Legal system and practical reason. Stuttgart: Steiner, p. 122. 


\section{8) RACIONALIDAD DEL COMPORTAMIENTO JUDICIAL}

Resolver de la misma manera los casos iguales, que es lo que esencialmente se pretende con el seguimiento del precedente, es condición de racionalidad del comportamiento del Poder Judicial. Y lo es tanto en sentido personal, es decir, respecto de las sentencias pronunciadas por cada uno de los jueces que lo integran, como en sentido institucional, esto es, respecto de las decisiones adoptadas por el conjunto de tribunales que lo constituyen.

En cuanto a la dimensión personal, parece inevitable coincidir con Bulygin en cuanto a que si un mismo juez se enfrenta a dos casos iguales y los resuelve de diversa manera sin justificar el cambio, actúa de manera irracional ${ }^{82}$. $\mathrm{Si}$, por el contrario, en el caso actual adopta la misma decisión que en el caso anterior o justifica el cambio, el juzgador actúa racionalmente. En similar sentido se expresa GASCón cuando afirma que el respeto al propio precedente constituye "la última trinchera de racionalidad" cuando el juzgador carece de criterios que le permitan elegir entre diversas interpretaciones posibles de una disposición ${ }^{83}$.

En cuanto a la dimensión institucional, conviene recordar que el conjunto de tribunales que conforman el Poder Judicial constituyen una unidad. Es lo que se denomina "unidad de jurisdicción", la que consiste en la instauración de un único Poder Judicial, que ejerce la función jurisdiccional de manera excluyente ${ }^{84}$. En otras palabras, "la potestad jurisdiccional es encomendada exclusivamente a los jueces y magistrados, integrantes del Poder Judicial, estándoles expresamente vedado a cualesquiera otros órdenes de funcionarios el ejercicio de aquella potestad" 85 . La unidad de la jurisdicción, por cierto, "no impide la existencia de la jurisdicción especializada" 86 .

Ahora bien, de la unidad de jurisdicción recién explicada se desprende una característica diversa de aquella: el Poder Judicial constituye una unidad en sí mismo y, por tanto, una unidad frente al ciudadano que litiga ${ }^{87}$. Esta unidad, que se puede denominar institucional, se produce

82 Conviene hacer presente que el autor argentino estima que resolver los casos iguales de la misma manera no es una exigencia jurídica, ni moral, sino condición de racionalidad de la decisión judicial. Ver Bulygin, Eugenio (2003) “Los jueces ¡crean Derecho?”. En Isonomía, abril, $\mathrm{N}^{\circ} 18$, p. 21.

83 Gascón Abellán (1993-1994) 215.

84 Ascencio Mellado, José María (2002) Introducción al Derecho procesal. Tirant lo Blanch, Valencia, segunda edición, p. 63.

85 Moreno Catena, Víctor, Cortés Domínguez, Valentín, y Gimeno Sendra, Vicente (2003) Introducción al derecho procesal. Colex, Madrid, cuarta edición, p. 57.

86 Melgar Adalid, Mario (2004) "Hacia un auténtico Tribunal Constitucional". En Cuestiones Constitucionales, $\mathrm{N}^{\circ} 11$, julio-diciembre, p. 148.

87 Esta unidad se refiere al conjunto de tribunales que integran el Poder Judicial y no al conjunto de órganos que ejercen jurisdicción. De ahí que el carácter unitario del Poder 
porque "sus decisiones son revisables, directa o indirectamente, por un único órgano supremo" 88 . En el caso chileno, la unidad institucional del Poder Judicial se evidencia en que los diversos órganos jurisdiccionales que intervienen en el conocimiento de un caso determinado ofrecen, en definitiva, una sola decisión final a través de los sistemas recursivos que permiten llegar hasta la Corte Suprema ${ }^{89}$, decisión por añadidura inamovible en virtud de la institución de la cosa juzgada ${ }^{90}$.

Si el Poder Judicial constituye una unidad desde el punto de vista institucional entonces se le puede exigir el mismo estándar de racionalidad que a cada juez respecto de sus propias decisiones. Pero en este caso solo respecto de aquellos tribunales recursivamente dependientes unos de otros, pues es precisamente la posibilidad de revisión hasta la Corte Suprema lo que genera dicha unidad institucional. De este modo, resulta posible sostener que si los tribunales recursivamente dependientes unos de otros se enfrentan a dos casos iguales y los resuelve de diversa manera sin justificar el cambio, actúan de manera irracional. Si, por el contrario, en el caso actual adoptan la misma decisión que en el caso anterior o justifican el cambio, actúan racionalmente. La racionalidad o irracionalidad predicada de la serie de tribunales recursivamente dependientes se predica, en definitiva, del Poder Judicial.

De esta manera, y en definitiva, el seguimiento del precedente se funda en la exigencia de racionalidad que pesa sobre el Poder Judicial, tanto en una dimensión personal como institucional.

\section{9) ECONOMÍA EN EL EJERCICIO DE LA JURISDICCIÓN}

La interpretación del Derecho con miras a la adecuada solución de un caso sometido a la decisión judicial exige un elevado esfuerzo intelectual por parte del juzgador. Esto se debe a que, de acuerdo con el modo en que actualmente se entiende la actividad judicial, una buena decisión es una decisión bien fundamentada ${ }^{91}$. Por lo mismo, es necesario estudiar

Judicial no resulta afectado por el carácter fragmentario que, como acertadamente destaca Andrés Bordalí, caracteriza al ejercicio de la jurisdicción en Chile. Al respecto ver Bordalí Salamanca, Andrés (2009) "Organización judicial en el Derecho chileno: un poder fragmentado”. En Revista Chilena de Derecho, Vol. 36, N² especialmente pp. 224-230.

88 Andaluz Vegacenteno, Horacio (2010) "La posición constitucional del Poder Judicial". En Revista de Derecho (Valparaíso), N XXXV, 2010, segundo semestre, p. 239.

89 Ver los artículos 767 y 780 del Código del Procedimiento Civil para materias civiles y de familia; artículos 373 y 376 del Código procesal Penal para asuntos penales; y artículos 483 y 483-A del Código del Trabajo en el ámbito laboral.

$90 \quad$ Artículos 175 a 177 del Código de Procedimiento Civil.

91 Atienza, Manuel (2011) "Cómo evaluar las argumentaciones judiciales". En Dianoia (México), Vol. 56, N 67, p. 115. 
para construir los argumentos que otorguen a la decisión la mejor fundamentación posible. Este esfuerzo intelectual y este estudio que preceden a toda interpretación bien justificada se traducen, desde una perspectiva económica, en tiempo y trabajo del juez.

Si se acepta esa premisa, resulta fácil concluir que repetir la tarea interpretativa frente a casos iguales genera un innecesario desgaste de recursos. Esto se debe a que frente a cada nuevo caso igual al ya resuelto permanecen abiertas todas las opciones interpretativas y, por tanto, (a) la selección de cualquiera de ellas y su justificación exige una nueva y antieconómica inversión de recursos por parte del juez ${ }^{92}$, y (b) se estimula la litigación fundada en la incertidumbre respecto de los resultados de la acción deducida ${ }^{93}$. En consecuencia, resultaría preferible destinar los mismos recursos, de esfuerzo intelectual, estudio y, por tanto, tiempo del juez, a la más adecuada solución de casos nuevos, que no cuentan con una interpretación que les resulte aplicable.

Por el contrario, si se siguen los precedentes, es decir, "si se aplican los criterios sentados en los casos previos, se ganará en tiempo y energía" para resolver los casos posteriores iguales al anterior ${ }^{94}$. En palabras de MENDONCA y Guibourg: "Al exigir igual trato para casos iguales, la teoría justifica que el juez del caso actual omita volver a reflexionar acerca del trato correspondiente al tipo de caso sometido a decisión" 95 . En este sentido, la ratio decidendi contenida en un determinado caso constituye la respuesta que el ordenamiento jurídico ofrece para todos los casos iguales a aquel. Esto se debe a que dicha ratio decidendi goza, al igual que otras fuentes normativas, de presunción de corrección, por lo que quien quiera apartarse de él deberá justificar el cambio de criterio ${ }^{96}$.

92 En el mismo sentido, expresa Figueroa García-Huidobro que "resulta deseconómico un sistema que obliga a considerar cada caso como si fuera un caso nuevo. En los sistemas donde no se reconoce el precedente, cada caso puede ser resuelto de cualquier manera; toda alternativa de solución que se presente será una alternativa disponible, de modo que cada caso puede estimarse como un caso nuevo". Ver Figueroa García-Huidobro (2000) 36.

93 De manera singularmente expresiva, sobre el punto afirma Alejandro Romero: "como la ideologia dominante ha proclamado falsamente que la jurisprudencia no vincula a nadie, el resultado práctico de tal proclama es que se puedan ejercitar acciones judiciales como actos aleatorios, que son comparables solo con el contrato de apuesta”. Ver Romero SEguel, Alejandro (2004) La jurisprudencia de los tribunales como fuente del Derecho. Una perspectiva procesal. Santiago de Chile: Jurídica de Chile, pp. 57 y 58.

94 SAGÜÉs, Néstor Pedro (2006) "La eficacia vinculante de la jurisprudencia de la Corte Suprema de Justicia en EE.UU. y Argentina”. En Estudios Constitucionales, año 4, N 1, p. 19.

95 Mendonca y Guibourg (2004) 183.

96 En el mismo sentido, Ferrer Mac Gregor, Eduardo, y Sánchez Gil, Rubén (2009) "Cosa Juzgada y Precedente en la Acción de Inconstitucionalidad Mexicana”. En Jhonny Tupayachi Sotomayor (Ed.). El precedente constitucional vinculante en el Perú: análisis, comentario y doctrina comparada. Lima, Perú: Adrus, Vol. 1, p. 781. 
En contra de este argumento se podría sostener que lo más económico sería contar con leyes y Códigos más completos, más claros y más ordenados. Una tal propuesta olvida que en la doctrina científica actual no existen discrepancias respecto de los inevitables problemas lingüísticos y lógicos que presentan los ordenamientos jurídicos ${ }^{97}$. Entre tales problemas se pueden mencionar, por ejemplo, la ambigüedad, las imprecisiones, la carga emotiva, las antinomias, las redundancias y las lagunas ${ }^{98}$. De este modo, la indeterminación que en muchos casos afecta al Derecho ha permitido confirmar lo ilusorio de aquella propuesta levantada por los ilustrados en el siglo XVIII, y desestimada a la luz de la evidencia acumulada hasta hoy ${ }^{99}$.

En definitiva, y desde un punto de vista económico, el seguimiento del precedente se traduce en una mejor asignación de los recursos destinados a la interpretación del Derecho por parte de los órganos jurisdiccionales, es decir, en una economía en el ejercicio de la jurisdicción.

\section{TEndencia COMParada}

Parece posible sostener que una de las tendencias más evidentes de las últimas décadas es el progresivo acercamiento de las dos grandes familias jurídicas occidentales, la del Civil Law y la del Common Law en lo relativo a sus fuentes ${ }^{100}$. En dicho contexto se inscribe la cada vez más frecuente incorporación del seguimiento de los precedentes establecidos por los órganos jurisdiccionales en los ordenamientos jurídicos del Civil $L a w^{101}$. Resultando imposible para la extensión de este artículo e innecesario desde el punto de sus objetivos analizar este fenómeno en todos los países en que se presenta, en lo que sigue solo se describe la situación en algunos ordenamientos jurídicos Iberoamericanos en los que se evidencia dicha tendencia, lo que ofrece un adecuado panorama del entorno jurídico y cultural al que pertenece Chile ${ }^{102}$.

$97 \quad$ DE Asís Roig (1995) 180.

98 Al respecto ver, por ejemplo, Nino, Carlos Santiago (2003). Introducción al análisis del Derecho. Barcelona: Ariel, undécima edición, pp. 259-289; y Ross, Alf (1994). Sobre el Derecho y la Justicia. Buenos Aires: Eudeba, quinta edición, pp. 119-131.

99 Con acierto expresa Alf Ross que es erróneo "creer que un texto puede ser tan claro que es imposible que suscite dudas en cuanto a su interpretación". Y agrega: "Este punto de vista está, empero, difundido". Ross (1994) 130 y notal al pie 9 de la misma p.

100 Legare, Santiago, y Rivera, Julio César (2006). "Naturaleza y dimensiones del Stare decisis". En Revista Chilena de Derecho, Vol. 23, № 1, p. 110, especialmente nota al pie 10.

101 Taruffo, Michelle (2007). "Precedente y jurisprudencia". En Revista Precedente (Universidad ICESI), especialmente pp. 85-87.

102 Luego de analizar, en una obra colectiva, el efecto de los precedentes en Alemania, España, Estados Unidos, Finlandia, Francia, Noruega, Polonia, Reino Unido, Suecia y Unión Europea, MacCormick y Summers concluyen que la primera gran similitud es que el 
En Argentina se reconoce fuerza vinculante a ciertas sentencias y a determinados acuerdos denominados plenos o plenarios emanados de tribunales colegiados ${ }^{103}$. En el caso particular de la Corte Suprema, y pese a ciertas vacilaciones iniciales y a ciertas precisiones frente a situaciones especiales, la misma Corte ha sostenido que su jurisprudencia debe ser seguida por los demás tribunales en todos los ámbitos normativos (constitucional, civil, penal, laboral, etcétera), a menos que el juez inferior cuente con razones para apartarse del precedente ${ }^{104}$.

El Tribunal Constitucional de Colombia ha sostenido de manera reiterada que los jueces y tribunales del país están obligados a seguir los precedentes establecidos por el Consejo de Estado en lo contencioso administrativo y por la Corte Suprema en la jurisdicción ordinaria ${ }^{105}$. La inobservancia de estos precedentes sin justificar adecuadamente el cambio de doctrina, ha precisado el mismo órgano jurisdiccional, puede configurar el delito de prevaricación y constituye una causal de interposición del recurso de tutela por infracción a derechos fundamentales ante el Tribunal Constitucional ${ }^{106}$.

El seguimiento del precedente también se encuentra establecido en República Dominicana, mediante el recurso de casación, cuya finalidad es mantener la unidad de la jurisprudencia nacional ${ }^{107}$. Este objetivo ha sido explicado por la Suprema Corte de Justicia de República Dominicana en el sentido que se deben seguir los precedentes. Al respecto sostuvo que la unidad de la jurisprudencia a que tiende dicho recurso "asegura la obtención de una justicia predecible, cualidad que ha sido reconocida por la doctrina como una garantía de dos de los principios fundamentales de nuestro sistema judicial, a saber, la igualdad de todos ante la ley y la seguridad juridica", lo que se alcanza resolviendo de la misma manera los casos iguales ${ }^{108}$.

precedente ahora juega una parte significativa en la toma de decisiones judiciales y en el desarrollo del Derecho en todos los países y tradiciones jurídicas que han sido revisados. Ver MacCormick y Summers (1997) 531-532.

SAGÜÉs (2006) 24.

Así lo explica Julia SÁnchez SÁnchez, con cita de sucesivas sentencias que van delineando esta perspectiva jurisprudencial de la Corte Suprema de Argentina. Al respecto ver SÁnCHEZ SÁnchez, Julia (2009). "Efecto de las sentencias constitucionales en el Derecho argentino". En Cuestiones Constitucionales (UNAM), $\mathrm{N}^{\circ} 21$, julio-diciembre, especialmente pp. 308 y 309.

Tribunal Constitucional de Colombia, 10 de abril de 2013, Rol No T-199/13, que en este punto cita su sentencia Rol No T-1023 de 2006.

TC de Colombia, Rol N ${ }^{\circ}$ T-199/13, que en este sentido cita sus Sentencias Rol N C-539 de 2011 y Rol No T-656 de 2011.

Artículo $2^{\circ}$ de la ley 3726, de República Dominicana.

En este mismo sentido, se declara en el Boletín del Observatorio de Justicia y Género del Poder Judicial de República Dominicana, $N^{\circ} 1$, noviembre de 2010, p. 8: "Sin esta unidad de la jurisprudencia que la Corte de Casación asegura a través de sus sentencias interpretando la ley, afirman algunos autores, la unidad de la legislación y la igualdad de todos los ciudadanos ante la ley, no sería más que una ilusión”. 
En Perú la legislación exige a los tribunales el seguimiento de los precedentes vinculantes emanados tanto del Tribunal Constitucional como de la Corte Suprema. En efecto, en el caso del primero la ley procesal constitucional dispone que el propio Tribunal deberá determinar en qué casos su sentencia constituye un precedente vinculante ${ }^{109}$, el que resulta obligatorio para la totalidad de los órganos del Estado, incluidos los tribunales de Justicia ${ }^{110}$. En el caso de la Corte Suprema de Perú, la ley orgánica del Poder Judicial dispone que las sentencias de la Corte Suprema que esta misma determine tienen el carácter de precedente vinculante respecto del Poder Judicial ${ }^{111}$.

En fin, y sin ánimo de ser exhaustivos, la incorporación del seguimiento del precedente se observa también en Venezuela y en El Salvador. En Venezuela la Constitución dispone expresamente que el seguimiento de los precedentes establecidos por la Sala Constitucional del Tribunal Supremo es imperativo, no solo para el resto de los tribunales del país, sino también para las demás Salas de la misma Corte ${ }^{112}$. En Venezuela la infracción del precedente es motivo de nulidad, desde que se puede deducir el recurso de casación en contra de resoluciones judiciales que se apartan del precedente establecido en tres sentencias consecutivas emanadas de la Corte Suprema del país ${ }^{113}$.

Por último, y aunque no se trata de una norma vigente, conviene mencionar que en España el anteproyecto de Ley Orgánica del Poder Judicial establece como causal de casación la inobservancia de la ratio decidendi establecida en dos o más sentencias de una misma sala del Tribunal Supremo. Además, dispone que el mismo Tribunal determinará trimestralmente qué fundamentos de sus sentencias constituyen doctrina jurisprudencial vinculante, la que será de obligada aplicación para todos los jueces y tribunales en el ejercicio de la potestad jurisdiccional ${ }^{114}$.

\footnotetext{
109 Artículo $7^{\circ}$ del Código Procesal Constitucional de Perú.

110 Figueroa Gutarra (sin fecha) 8.

111 Artículo 22 de la Ley Orgánica del Poder Judicial de Perú.

112 Dispone el artículo 335 de la Constitución de Venezuela: "El Tribunal Supremo de Justicia garantizará la supremacía y efectividad de las normas y principios constitucionales; será el máximo y último intérprete de esta Constitución y velará por su uniforme interpretación y aplicación. Las interpretaciones que establezca la Sala Constitucional sobre el contenido o alcance de las normas y principios constitucionales son vinculantes para las otras Salas del Tribunal Supremo de Justicia y demás tribunales de la República".

113 En El Salvador el recurso de casación procede, entre otras razones, y en lo que interesa al presente trabajo, por violación o interpretación errónea de la doctrina legal. La misma ley explica que la doctrina legal es la jurisprudencia establecida por los tribunales de Casación, en tres sentencias uniformes y no interrumpidas por otra en contrario, siempre que lo resuelto sea sobre materias idénticas en casos semejantes (artículo preliminar y $\mathrm{N}^{\circ}$ s 1 y 2 del artículo $3^{\circ}$ de la ley de casación).

114 Artículos 31 y 32 del Anteproyecto de Ley Orgánica del Poder Judicial.
} 
Lo expuesto evidencia que el seguimiento del precedente se extiende por diversos ordenamientos jurídicos iberoamericanos, en algunas ocasiones por el solo impulso de los propios órganos jurisdiccionales (Argentina, Colombia, República Dominicana) y en otras en virtud de la regulación establecida en la legislación (Perú, Venezuela, El Salvador) o en proyectos de legislación (España).

\section{CONCLUSIONES}

Los razonamientos expuestos a lo largo del presente trabajo permiten sostener esencialmente dos cosas respecto del seguimiento del precedente en el ordenamiento jurídico chileno.

En primer lugar, que ninguna de las objeciones levantadas en contra de esta pretensión y que se han analizado son realmente atendibles. En efecto, la vinculación prima facie al precedente no atenta en contra del sistema de fuentes del Civil Law, no lesiona la justicia material, no afecta la independencia judicial, y no empobrece ni provoca la petrificación del Derecho.

En segundo lugar, que el seguimiento del precedente en el ámbito procesal civil y, en general, en todos los ámbitos procesales incrementa la seguridad jurídica, viabiliza la justicia formal, colabora a la corrección del discurso judicial, es condición de racionalidad de la interpretación judicial del Derecho, genera economía procesal y constituye una tendencia en diversos ordenamientos jurídicos iberoamericanos de la familia europeo continental.

De este modo, existen sólidas razones para que el seguimiento del precedente se transforme en una realidad en Chile, sea en virtud de la praxis jurisprudencial, esencialmente de la Corte Suprema, o por vía del impulso legislativo. La cuestión, como se ha visto, no es normativa, sino ante todo cultural. Las resistencias se asientan en creencias, extendidas, pero equivocadas, respecto del rol de la jurisprudencia en el contexto del Civil Law y particularmente en el ordenamiento jurídico chileno. Por el contrario, los beneficios que derivan de admitir e introducir decididamente el seguimiento del precedente se sostienen en argumentos axiológicos, lógicos, económicos e incluso iusfundamentales. Dar este paso implicará, evidentemente, nuevos análisis y sobre todo una nueva manera de ejercer el Derecho por parte de los operadores jurídicos. Sin embargo, los beneficios que reporta el seguimiento del precedente bien justifican hacer ese esfuerzo. 


\section{BIBLIOGRAFÍA}

\section{LIBROS}

- Alessandri R., Arturo, Somarriva U., Manuel, y Vodanovic H., Antonio (1998). Tratado de Derecho civil. Santiago de Chile: Jurídica de Chile, t. I.

- Alexy, Robert (1999). Teoría de la argumentación jurídica. Traducción de Manuel Atienza e Isabel Espejo. Madrid: Centro de Estudios Constitucionales, primera reimpresión.

- Alexy, Robert (2001). Teoría de los derechos fundamentales. Traducción de Ernesto Garzón Valdés. Madrid: Centro de Estudios Políticos y Constitucionales.

- Ascencio Mellado, José María (2002). Introducción al Derecho procesal. Tirant lo Blanch, Valencia, segunda edición.

- Barranco Avilés, María del Carmen (2004). Derechos y decisiones interpretativas. Madrid: Marcial Pons.

- Casarino Viterbo, Mario (2008). Manual de Derecho procesal, tomo I, Jurídica de Chile, Santiago de Chile, reimpresión de la sexta edición.

- Cea Egaña, José Luis (2004). Derecho constitucional chileno. Santiago de Chile: Ediciones Universidad Católica de Chile, t. II.

- Claro Solar, Luis (1992): Explicaciones de Derecho civil chileno y comparado. Santiago de Chile: Jurídica de Chile, Vol. I, T.I.

- DE Asís Roig, Rafael (1995). Jueces y normas. La decisión judicial desde el ordenamiento. Madrid: Marcial Pons.

- DE Asís Roig, Rafael (2005). El juez y la motivación en el Derecho. Madrid: Dykinson.

- Duxbury, Neil (2008). The nature and authority of precedent. United Kingdom: Cambridge University Press.

- Escandón Alomar, Jesús (2008). Curso de Introducción al Derecho. Concepción: Universidad de Concepción.

- Evans de la Cuadra, Enrique (2004). Los derechos constitucionales. Tercera edición actualizada. Santiago de Chile: Jurídica de Chile, tomo II.

- Ferrajoli, Luigi (1998). Derecho y razón. Teoría del garantismo penal. Traducción de Perfecto Andrés Ibáñez, Alfonso Ruiz Miguel, Juan Carlos Bayón Mohino, Juan Terradillos Basoco y Rocío Cantarero Bandrés. España: Trotta, tercera edición.

- Ferrer Mac Gregor, Eduardo, y Sánchez Gil, Rubén (2009). "Cosa Juzgada y Precedente en la Acción de Inconstitucionalidad Mexicana”. En Jhonny Tupayachi Sotomayor (Ed.). El precedente 
constitucional vinculante en el Perú: análisis, comentario y doctrina comparada. Lima, Perú: Adrus, vol. 1, pp. 767-790.

- Larenz, Karl (1994). Metodología de la ciencia del Derecho. Traducción de Marcelino Rodríguez Molinero. Barcelona, Ariel.

- Latorre, Ángel (1991). Introducción al Derecho. Barcelona: Ariel, séptima edición.

- MacCormick, Neil, y Summers, Robert S. (eds.) (1997). Interpreting precedents. A comparative study. Aldershot-Brookfield: Ashgate Dartmouth.

- Mendonca, Daniel, y Guibourg, Ricardo A. (2004). La odisea constitucional. Constitución, teoría y método. Madrid: Marcial Pons.

- Molina Guaita, Hernán (2006). Derecho constitucional. Santiago de Chile: LexisNexis.

- Montesquieu (1984). Del espiritu de las leyes. (Traducción de Nicolás Estévanez). Buenos Aires, Editorial Heliasta, sexta edición.

- Moreno Catena, Víctor, Cortés Domínguez, Valentín, y Gimeno Sendra, Vicente (2003). Introducción al derecho procesal. Colex, Madrid, cuarta edición.

- Nino, Carlos Santiago (2003). Introducción al análisis del Derecho. Undécima edición. Barcelona: Ariel.

- Peces-Barba Martínez, Gregorio, con la colaboración de De Asís Roig, Rafael; Fernández Liesa, Carlos R.; y Llamas Cascón, Ángel (1999). Curso de derechos fundamentales. Madrid, Universidad Carlos III de Madrid y Boletín Oficial del Estado, primera reimpresión.

- Peczenik, Aleksander (1997). "The binding force of precedent". En MacCormick, Neil, y Summers, Robert S. (eds.) (1997). Interpreting precedents. A comparative study. Aldershot-Brookfield: Ashgate Dartmouth, pp. 461-479.

- Rescher, Nicholas (1993). La racionalidad. Una indagación filosófica sobre la naturaleza y la justificación de la razón. Traducción de Susana Nuccetelli. Madrid: Tecnos.

- Romero Seguel, Alejandro (2004). La jurisprudencia de los tribunales como fuente del Derecho. Una perspectiva procesal. Santiago de Chile: Jurídica de Chile.

- Ross, Alf (1994). Sobre el Derecho y la Justicia. Quinta edición. Buenos Aires: Eudeba.

- Sarmiento García, Luis E. (1984). Introducción al Derecho. Buenos Aires: Abeledo Perrot.

- Serra Cristóbal, Rosario (2004). La libertad ideológica del juez. Valencia: Tirant lo Blanch. 
- Squella Narducci, Agustín (2011). Introducción al Derecho, Santiago de Chile: Jurídica de Chile, segunda edición.

- Verdugo Marinkovic, Mario, Pfeffer Urquiaga, Emilio, y Nogueira Alcalá, Humberto (2002). Derecho constitucional. Segunda edición. Santiago de Chile: Jurídica de Chile, t. I.

\section{Capítulos de libros}

- Salmerón, Fernando (1991). “Comentario a la ponencia de Francisco Miró Quesada”. En Sobrevilla, David (compilador). El Derecho, la politica y la ética (Actas del II Coloquio AlemánLatinoamericano de Filosofía, Lima, 1987). México: Siglo XXI, pp. $138-150$.

- Tavolari, Raúl (2006) "Reflexiones sobre la Corte Suprema chilena”, en Berizonce, Hitter y Oteíza (Coords.), El papel de los Tribunales Superiores, ubinzan-Culzoni, Buenos Aires, pp. 471-500.

\section{ARTÍCUlOS EN SOPORTE FÍSICO}

- Díaz García, L. Iván; Alarcón García, Sofía; Cempe Cempe, Katerine; Garrido Esparza, Luis Alejandro; y Zúñiga Garrido, Alejandro (2014). "Seguimiento del precedente por la Corte Suprema de Chile en materia laboral. Estudio empírico del recurso de unificación de jurisprudencia”. En Revista Chilena de Derecho. Vol. 41, N³, pp. 1105-1131.

- García Amado, Juan Antonio (1994). "Justicia, democracia y validez del Derecho en Jürgen Habermas". En Koch, Hans-Joachm, y Neumann, Ulfrid (eds.). Legal system and practical reason. Stuttgart: Steiner, pp. 119-128.

- Halpern, Cecily, y Humeres, Héctor (2010). "La intervención de la Corte Suprema en la nueva justicia del trabajo: el recurso de unificación de jurisprudencia”. En: Actualidad Juridica, Universidad del Desarrollo año XI, $N^{\circ} 21$, pp. 345-374.

- Llewellyng, Karl (1989): The case law system in America. Translate from the German by Michael Ansaldi. Chicago: The University of Chicago Press.

- Maltz, Earl (1988). The nature of precedent. North Carolina Law Review, January.

- Nieva Fenoll, Jordi (2006). "La reforma de la labor del Tribunal Supremo y la unificación de doctrina. Perspectivas de la introducción del modelo anglosajón en nuestro Derecho". En Diario La Ley, sección Doctrina, 4 de enero de 2006, año XXVII, Editorial La Ley. 


\section{ARTÍCULOS EN SOPORTE INFORMÁTICO}

- Aarnio, Aulis (1990). La tesis de la única respuesta correcta y el principio regulativo del razonamiento jurídico". Traducción de Josep Aguiló Regla. En Doxa, N ${ }^{\circ}$ 8, pp. 2338. Disponible en: http://www.cervantesvirtual.com/servlet/ SirveObras/01471734433736095354480/index.htm. [Fecha de consulta: 27 de septiembre de 2007].

- Alchourrón, Carlos (2000). "Sobre Derecho y lógica". Traducción de Jorge L. Rodríguez con la colaboración de Sergio A. Militello. En Isonomía, octubre $\mathrm{N}^{\circ} 13$, pp. 1133. Disponible en: http://www.cervantesvirtual.com/servlet/ SirveObras/01474064433736395354480/index.htm. [Fecha de consulta: 2 de agosto de 2007].

- Andaluz Vegacenteno, Horacio (2010). "La posición constitucional del Poder Judicial". En Revista de Derecho (Valparaíso), $\mathrm{N}^{\circ}$ XXXV, segundo semestre, pp. 229-243. Disponible en: http://www.scielo.cl/pdf/rdpucv/n35/a07.pdf. [Fecha de consulta: 20 de abril de 2014].

- Atienza, Manuel (2011). "Cómo evaluar las argumentaciones judiciales". En Dianoia (México), Vol. 56, N 67, pp. 113-124. Disponible en: http://www.scielo.org.mx/scielo.php?script=sci_art text\&pid=S0185-24502011000200006. [Fecha de consulta: 15 de octubre de 2014].

- Bordalí Salamanca, Andrés (2009). "Organización judicial en el Derecho chileno: un poder fragmentado". En Revista Chilena de Derecho, Vol. 36, $\mathrm{N}^{\circ}$ 2, pp. 215-244. Disponible en: http://www.scielo.cl/scielo.php?script=sci_arttext\&pid =S0718-34372009000200002 [Feca de consulta: 26 septiembre 2014].

- Bordalí Salamanca, Andrés (2013). "La independencia de los jueces en la aplicación de la ley dentro de la organización judicial chilena". En Revista Chilena de Derecho, Vol. 40, $\mathrm{N}^{\circ} 2$, agosto 2013, pp. 609-634. Disponible en: http://www.scielo.cl/scielo. php?pid=S0718-34372013000200010\&script=sci_arttext. [Fecha de consulta: 3 de noviembre de 2014].

- Bravo-Hurtado, Pablo (2013). "Hacia los precedentes en Chile: Reforma procesal Civil y fuentes del Derecho". En Revista Chilena de Derecho, Vol. 40, N² 2, 2013, pp. 549-576. Disponible en: http:// www.scielo.cl/pdf/rchilder/v40n2/art08.pdf. [Fecha de consulta: 15 de octubre de 2014].

- Bulygin, Eugenio (2003). "Los jueces ¿crean Derecho?". En Isonomia, abril, $\mathrm{N}^{\circ} 18$, pp. 7-25. Disponible 
en: http:// www.cervantesvirtual.com/servlet/ SirveObras/01482529789055928540035/index.htm. [Fecha de consulta: 2 de agosto de 2007].

- Castagnola, Andrea (2010). "La diversidad institucional de los poderes judiciales provinciales en Argentina desde una perspectiva histórica". En Postdata (Buenos Aires), Vol. 15, $\mathrm{N}^{\circ}$ 2, jul. dic. sin paginación. Disponible en: http://www.scielo.org.ar/scielo. php?script=sci_arttext \&pid=S1851-96012010000200002\&lng=es\& nrm=iso\&tlng=es. [Fecha de consulta: 3 de noviembre de 2014].

- Comanducci, Paolo (1999). "Igualdad liberal". [Fecha de consulta: 7 de febrero de 2009]. Disponible en: www.palermo. edu/derecho/publicaciones/pdfs/revista_juridica/n3N2Octubre1998/032Juridica03.pdf.

- Couso Salas, Jaime (2007). "El rol uniformador de la sala penal de la Corte Suprema. Anatomía de un fracaso". En Revista de Derecho, Universidad Austral, Vol. XX - No 2 - diciembre, pp. 147-172. Disponible en: http://www.scielo.cl/pdf/revider/v20n2/art07.pdf. [Fecha de consulta: 23 de octubre de 2014].

- Cueto Rúa, (1998). "La axiología jurídica y la selección de métodos de interpretación”. En Doxa (Alicante), N²1-II, pp. 111-119. Disponible en: www.cervantesvirtual.com/servlet/ SirveObras/23582844322570740087891/cuaderno21/volII/ DOXA21Vo.II_09.pdf. [Fecha de consulta: 2 de octubre de 2007].

- DE Asís Roig, Rafael (2004). "Imparcialidad, Igualdad y obediencia en la actividad judicial". En Doxa (Alicante), $\mathrm{N}^{\circ} 15-16$, pp. 913-928. Disponible en: www.cervantesvirtual.com/servlet/ SirveObras/01361620824573839199024/cuaderno15/volII/ doxa15_23.pdf. [Fecha de consulta: 11 de abril de 2008].

- Del Río Ferreti, Carlos (2010). “Tres apuntes sobre el recurso de nulidad y el enjuiciamiento fácticos a propósito de tres fallos de la Ilustrísima Corte de Apelaciones de La Serena". En Revista de Derecho (Coquimbo), año 17, $\mathrm{N}^{\circ}$ 2, pp. 131-146. Disponible en: http://www.scielo.cl/pdf/rducn/v17n1/art06.pdf. [Fecha de consulta: 20 de abril de 2015].

- Delgado Castro, Jordi, y Díaz García, L. Iván (2011). "La unificación de jurisprudencia pretendida por el recurso extraordinario. Ventajas y problemas". En Revista de Derecho, Universidad Católica del Norte, Vol. 18, $\mathrm{N}^{\circ}$ 2, pp. 275304. Disponible en: http://www.scielo.cl/scielo.php?script=sci arttext\&pid=S0718-9753201 1000200010\&lng=es\&nrm=iso. [Fecha de consulta: 7 de marzo de 2012].

- Espinosa Quintero, Leonardo (2010). "Hacia la arbitrabilidad como regla general en el sistema actual colombiano". En Revista de 
Derecho (Barranquilla), $\mathrm{N}^{\circ}$ 3, julio-diciembre 2010, pp. 177-206. Disponible en: http://www.scielo.unal.edu.co/scielo.php?script=sci_ arttext\&pid=S0121-86972010000200008\&lng=es\&nrm=iso. [Fecha de consulta: 10 septiembre 2014 ].

- Figueroa García-Huidobro., Rodolfo (2000). "Igualdad y discriminación”. Disponible en: www.udp.cl/derecho/ derechoshumanos/publicaciones/10/figueroa.pdf. [Fecha de consulta: 22 de julio de 2008].

- Figueroa Gutarra, Edwin (sin fecha). "Precedentes vinculantes: ¿consolidación normativa o restricciones a las facultades interpretativas de los jueces?". Disponible en: http://www. gacetaconstitucional.com.pe/sumario-cons/doc-sum/Edwin $\% 20$ Figueroa\%20Gutarra\%20-\%20Gaceta\%20Constitucional\%2059. pdf. [Fecha de consulta: 7 agosto 2014].

- Garrido Gómez, María Isabel (2009). "La predecibilidad de las decisiones judiciales". En Ius et Praxis, vol. 15, $\mathrm{N}^{\circ}$ 1, pp. 55-72. Disponible en: http://www.scielo.cl/scielo.php?script=sci_arttext\&p $\mathrm{id}=$ S0718-00122009000100003. [Fecha de consulta: 15 de octubre de 2014].

- Gascón Abellán, Marina (1993-1994). "Igualdad y respeto al precedente". En Derechos y Libertades, año 1, $\mathrm{N}^{\circ}$ 2, pp. 211-227. Disponible en: http://dialnet.unirioja.es/servlet/articulo?codigo= 175011\&orden=187898\&info=link. [Fecha de consulta: 10 mayo 2009], p. 225.

- Herrera Carbucia, Manuel Ramón (2006). "Importancia de la unidad de la jurisprudencia laboral. Análisis y discusión”. En Gaceta Laboral, Vol. 12, $\mathrm{N}^{\circ}$ 1, pp. 123-142. Disponible en: http://www. scielo.org.ve/scielo.php?...85972006000100006. [Fecha de consulta: 7 de mayo de 2009].

- Legare, Santiago, y Rivera, Julio César (2006). "Naturaleza y dimensiones del Stare decisis". En Revista Chilena de Derecho, Vol. 23, $\mathrm{N}^{\circ}$ 1, pp. 109-124. Disponible en: http://www.scielo.cl/pdf/ rchilder/v33n1/art07.pdf. [Fecha de consulta: 6 de febrero de 2009].

- Marinoni, Luiz Guilherme (2012). "El precedente en la dimensión de la seguridad jurídica”. En Ius et Praxis, Año 18, No 1, pp. 249266. Disponible en: http://www.scielo.cl/scielo.php?script=sci_ar ttext\&pid=S0718-00122012000100008. [Fecha de consulta: 10 septiembre 2014].

- Marshall Barberán, Pablo (2010). "El Estado de Derecho como principio y su consagración en la Constitución Política”. En Revista de Derecho, Universidad Católica del Norte, año 17, N², pp. 185204. Disponible en: http://www.scielo.cl/scielo.php?pid=S0718- 
97532010000200008\&script=sci_arttext. [Fecha de consulta: 23 de octubre de 2014].

- Melgar Adalid, Mario (2004). "Hacia un auténtico Tribunal Constitucional". En Cuestiones Constitucionales, $\mathrm{N}^{\circ} 11$, juliodiciembre, pp. 133-155. Disponible en: http://webcache. googleusercontent.com/search?q=cache:nRMONd76EWAJ:www. redalyc.org/pdf $/ 885 / 88501104 . \mathrm{pdf}+\& \mathrm{~cd}=2 \& \mathrm{hl}=\mathrm{es} \& \mathrm{ct}=\mathrm{clnk} \& \mathrm{gl}=\mathrm{cl}$. [Fecha de consulta: 20 de abril de 2015].

- Parra, María Victoria (2004). "El precedente judicial en el Derecho comparado". En Criterio Jurídico, $\mathrm{N}^{\circ} 4$, pp. , pp. 241-262. Disponible en: http://www.puj.edu.co/banners/EL_ PRECEDENTE_JUDICIAL.pdf. [Fecha de consulta: 13 de febrero de 2009]

- Remón Peñalver, Jesús (2006). "La lucha por la seguridad jurídica". Madrid: La Ley, pp. 65-85. Disponible en: http://www.uria.com/ documentos/publicaciones/1606/documento/art05.pdf? id=2163. [Fecha de consulta: 23 de diciembre de 2014].

- Rodríguez Collao, Luis, y Ossandón Widow, María Magdalena (2005). "Aspectos sistemáticos y político-criminales de la prevaricación admnistrativa”. En Revista de Derecho (Valparaíso), vol. XXVI, segundo semestre, pp. 405-418. Disponible en: http://www. redalyc.org/pdf/1736/173620162013.pdf. [Fecha de consulta: 20 de abril de 2015].

- SAgüÉs, Néstor Pedro (2006). "La eficacia vinculante de la jurisprudencia de la Corte Suprema de Justicia en EE.UU. y Argentina”. En Estudios Constitucionales, año 4, $\mathrm{N}^{\circ} 1$, pp. 17-32. Disponible en: http://www.cecoch.cl/docs/pdf/revista_ano4_1/ revista_ano4_1_1.pdf. [Fecha de consulta: 12 de septiembre de 2014].

- SÁnchez Sánchez, Julia (2009). "Efecto de las sentencias constitucionales en el Derecho argentino". En Cuestiones Constitucionales (UNAM), $\mathrm{N}^{\circ} 21$, julio-diciembre, pp. 295318. Disponible en: http://biblio.juridicas.unam.mx/revista/ CuestionesConstitucionales/indice.htm? $\mathrm{n}=21$. [Fecha de consulta: 15 de septiembre de 2014].

- Taruffo, Michelle (2007). "Precedente y jurisprudencia". En Revista Precedente (Universidad ICESI), pp. 85-99. Disponible en: https://www.icesi.edu.co/revistas/index.php/precedente/article/ download/1434/1831. [Fecha de consulta: 12 de septiembre de 2014].

- Whittaker, Simon (2008). "El precedente en el derecho inglés: una visión desde la ciudadela". Traducción de Cristián Banfi del Río. En Revista Chilena de Derecho, vol. 35, N 1, pp. 37-83. Disponible en: 
< http://www.scielo.cl/scielo.php?script=sci_arttext\&pid=S0718$34372008000100003 \& \operatorname{lng}=$ es\&nrm=iso $>$. [Fecha de consulta 7 mayo 2009].

\section{NORMAS JURÍDICAS}

- Anteproyecto de Ley Orgánica del Poder Judicial de España. Disponible en: http://www.mjusticia.gob.es/cs/Satellite/ es/1215198252237/ALegislativa_P/1288774452773/Detalle.html. [Fecha de consulta: 9 de octubre de 2014].

- Código Civil de Chile, decreto con fuerza de ley $\mathrm{N}^{\circ} 1$, de 16 de mayo de 2000. Publicado en el Diario Oficial de Chile de 30 de mayo de 2000.

- Código de Procedimiento Civil de Chile, ley 1552. Publicado en el Diario Oficial de 30 de agosto de 1902. Disponible en: http://www. leychile.cl/N?i=22740\&f=2007-11-12\&p [Fecha de consulta: 23 de abril de 2013].

- Código del Trabajo de Chile, decreto con fuerza de ley 1 del Ministerio del Trabajo y Previsión Social, de 24 de enero de 1994. Disponible en: http://www.leychile.cl/N?i=207436\&f=2012-0808\&p=. [Fecha de consulta: 7 de agosto de 2013].

- Código Procesal Penal de Chile, ley 19.696. Publicado en el Diario Oficial de 12 de octubre de 2000. Disponible en: http://www. leychile.cl/N?i=176595\&f=2012-06-02\&p [Fecha de consulta de 23 abril de 2013].

- Código Procesal Constitucional de Perú, ley 28.237.

- Constitución Política de la República de Chile, decreto 100 del Ministerio Secretaría General de la Presidencia, de 22 de septiembre de 2005.

- Constitución de la República Bolivariana de Venezuela, Gaceta Oficial Extraordinaria No 36.860 de 30 de diciembre de 1999. Disponible en: http://www.oas.org/dil/esp/Constitucion_Venezuela. pdf. [Fecha de consulta: 12 de enero de 2015].

- Ley 3726, de República Dominicana. Disponible en: http://www. comisionadodejusticia.gob.do/index.php?option $=$ com_phocadownlo ad\&view=category\&download=64:3726\&id=21. [Fecha de consulta: 16 de abril de 2013]. 
- Ley de casación de El Salvador.

- Ley orgánica del Poder Judicial de Perú.

\section{JURISPRUDENCIA}

- Tribunal Constitucional de Colombia T-199/13, de 10 de abril de 2013. Disponible en: http://www.corteconstitucional.gov.co/ relatoria/2013/T-199-13.htm. [Fecha de consulta: 8 de octubre de 2014].

- Tribunal Constitucional de Chile, 11 de diciembre de 2012, rol No 2041-2011, Requerimiento de inaplicabilidad por inconstitucionalidad de Inversiones Alce S.A. respecto del artículo 115 , inciso $1^{\circ}$ del Código Tributario, en los autos sobre reclamación Tributaria, caratulados "Inversiones Alce S.A. con Servicio de Impuestos Internos", del que conoce el Tribunal Tributario de la ciudad de Temuco, bajo el Rol No 10.057. Disponible en: http:// www.tribunalconstitucional.cl/wp/ver.php?id=2688. [Fecha de consulta: 30 de octubre de 2014].

- Tribunal Constitucional de Chile, 30 de diciembre de 2008, rol $\mathrm{N}^{\circ}$ 1243-2008, Control de constitucionalidad del proyecto de ley, aprobado por el Congreso Nacional, que fortalece y perfecciona la jurisdicción tributaria (Boletín $\mathrm{N}^{\circ}$ 3139-05). Disponible en: http:// www.tribunalconstitucional.cl/wp/ver.php?id=1076. [Fecha de consulta: 30 de octubre de 2014].

\section{Documentos}

- Asamblea General de las Naciones Unidas (1985). Principios básicos relativos a la independencia de la judicatura. Resoluciones 4032, del 29 de noviembre de 1985 y $40 \mathrm{i} 146$ del 13 de diciembre de 1985. Disponible en: http://scm.oas.org/pdfs/2014/ CP32727TEXTUAL.pdf. [Fecha de consulta: 13 de noviembre de 2014].

- Boletín del Observatorio de Justicia y Género del Poder Judicial de República Dominicana, número 1, noviembre de 2010. Disponible en http://www.observatoriojusticiaygenero.gob.do/documentos/ boletines/difnag/primer_boletin.pdf [ Fecha de consulta 16 de abril de 2013]. 